REVESCO. Revista de Estudios Cooperativos ISSN: $1885-8031$

\title{
La Cooperativa de Iniciativa Social: un modelo de Empresa Social en España
}

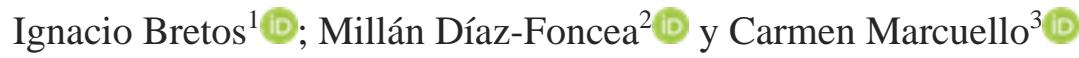

Recibido: 9 de enero de 2020 / Aceptado: 25 de febrero de 2020 / Publicado: 10 de julio de 2020

Resumen. Este artículo aborda una figura organizacional del ámbito de la Economía Social española apenas analizada hasta ahora en la literatura académica: la cooperativa de iniciativa social (CIS). A través de un análisis descriptivo, el artículo ofrece una primera aproximación para delimitar, cuantificar y caracterizar las cooperativas de iniciativa social en España. La investigación se basa fundamentalmente en los datos cedidos por los Registros autonómicos y provinciales de cooperativas. Dicha información ha permitido analizar el contexto y proceso de institucionalización en el que surgen las CIS en España, el marco normativo que las regula en cada comunidad autónoma, la cuantificación del número de CIS existentes en España y la evolución de la creación de estas entidades, su distribución geográfica, su tamaño en términos de número inicial de socios y capital social inicial, y su distribución sectorial. Además, se ha podido realizar también un análisis comparativo de las CIS con el conjunto del sector cooperativo. Los resultados permiten obtener el siguiente perfil: en 2017 existían 647 CIS activas en España, localizadas principalmente en Andalucía, Cataluña, País Vasco y Madrid. Las CIS son entidades de pequeño tamaño, que tienden a crearse con menos de 5 socios y un capital social inicial de menos de 5.000 euros. Su actividad se localiza fundamentalmente en los sectores de Educación y de Servicios sociales y sanitarios. El perfil obtenido para la CIS encaja perfectamente en la conceptualización europea de empresa social, al combinar una dimensión económica, social y de gobernanza democrática. En esta línea, contribuimos a la literatura internacional sobre empresa social, abordando los recientes llamamientos de diversos autores para comenzar a contrastar empíricamente las conceptualizaciones existentes de empresa social con la amplia variedad de modelos y experiencias que existen en el mundo. Así, el estudio se sitúa en una línea de trabajo emergente que está mapeando y analizando el surgimiento, desarrollo y características de distintas tipologías de empresa social en diferentes territorios.

Palabras clave: Cooperativa; Cooperativa de Iniciativa Social; Empresa Social; Economía Social; Impacto social; Innovación social.

Claves Econlit: A13; L31; O35; P13.

\section{[en] The Social Initiative Cooperative as a Social Enterprise model in Spain}

\begin{abstract}
This article examines an organizational form in the field of the Spanish Social Economy that has been neglected in the academic literature: the social initiative cooperative. Through a descriptive analysis, the article offers a first approach to delimit, quantify and characterize social initiative cooperatives in Spain. The research is based on the data provided by the regional and provincial Cooperative Registration Offices. This information allowed us to analyze the context and process of institutionalization in which social cooperatives emerged in Spain, the regulatory framework that governs them in each autonomous community, the quantification of the number of social cooperatives in Spain and the evolution of the creation of these organizations, their geographical distribution, their size in terms of the initial number of members and initial share capital, and their sectoral distribution. In addition, it was also possible to carry out a comparative analysis between social cooperatives and the cooperative sector as a whole. The findings yield the following profile: in 2017 there were 647 active social cooperatives in Spain, located mainly in the Autonomous Communities of Andalusia, Catalonia, the Basque Country and Madrid. Spanish social cooperatives are small sized organizations, which tend to be created mainly with less than 5 members and an initial share capital of less than $€ 5,000$. Their activity is mainly located in the sectors of Education and Social and Health Services. Likewise, the profile obtained for the Spanish social cooperative fits perfectly into the European concept of social enterprise, as it combines an economic, social and democratic governance dimension. We contribute to the international literature on social enterprise, addressing recent calls to empirically contrast existing conceptualizations of social enterprise with the wide variety of models and experiences that exist in the world. Thus, the study is situated within an incipient line of work that is mapping and analyzing the emergence, development and characteristics of different typologies of social enterprise in different territories.
\end{abstract}

Keywords: Cooperative; Social initiative cooperative; Social enterprise; Social economy; Social impact; Social innovation.

1 Universidad de Zaragoza, España.

Dirección de correo electrónico: ibretos@unizar.es.

2 Universidad de Zaragoza, España.

Dirección de correo electrónico: millan@unizar.es.

3 Universidad de Zaragoza, España.

Dirección de correo electrónico: cmarcue@unizar.es. 
Sumario. 1. Introducción. 2. La Cooperativa de Iniciativa Social española en el contexto internacional de la empresa social. 3. Metodología. 4. Marco normativo de las Cooperativas de Iniciativa Social en España. 5. Características básicas de las Cooperativas de Iniciativa Social en España. 6. Análisis comparado de las CIS con el sector cooperativo total y las cooperativas de trabajo asociado. 7. Conclusiones. 8. Referencias bibliográficas.

Cómo citar. Bretos, I.; Díaz-Foncea, M.; Marcuello, C. (2020) La cooperativa de iniciativa social: un modelo de empresa social en España. REVESCO. Revista de Estudios Cooperativos, vol. 135, e69186. https://dx.doi.org/10.5209/reve.69186.

\section{Introducción}

Desde el ámbito académico ha surgido una amplia literatura sobre empresa social y emprendimiento social, atraída por el importante papel de estas organizaciones en la consecución de fines de orientación social y medioambiental (Bretos et al., 2018a; Chaves y Monzón, 2018), mientras emplean métodos de gestión democrática (Cabaleiro Casa et al., 2019), operan con un elevado grado de competitividad en el mercado (Guzmán et al., 2019a, b) y desarrollan estrategias de mercado innovadoras (Bretos et al., 2018b). Como campo de investigación emergente, buena parte de la literatura se ha centrado en abordar la definición de empresa social y las teorías que mejor explican el surgimiento y naturaleza de estas organizaciones (Dacin et al., 2011; Teasdale, 2012; Kerlin, 2013; Choi y Majumdar, 2014). De hecho, siguen apareciendo estudios que tratan de contribuir a lograr una conceptualización y definición de empresa social aceptada universalmente (Salamon y Sokolowski, 2016; Bull y Ridley-Duff, 2019).

Más allá del acalorado debate conceptual, recientemente viene desarrollándose una línea de investigación que analiza de manera más empírica el surgimiento y factores de desarrollo de la empresa social en diferentes países, las características y prácticas de estas organizaciones, así como el funcionamiento de sus dimensiones económicas, sociales y de gobernanza. Especialmente a partir del proyecto ICSEM (International Comparison of Social Enteprise Models) coordinado por la red internacional de investigación EMES, han surgido varios estudios que avanzan en un análisis comparativo internacional de distintos modelos de empresa social y sus respectivos procesos de institucionalización en diferentes territorios (para una revisión, véase Defourny y Nyssens, 2017a; Díaz-Foncea, 2017).

En el caso de España, se han identificado tres tipologías básicas de empresa social en el ámbito de la Economía Social: las empresas de inserción, los centros especiales de empleo y las cooperativas de iniciativa social (Spear et al., 2009; Díaz-Foncea y Marcuello, 2012, Díaz Foncea y Marcuello, 2014). Si bien las empresas de inserción y los centros especiales de empleo han sido ampliamente analizados en la literatura científica, el conocimiento sobre las cooperativas de iniciativa social (en adelante, CIS) es extremadamente limitado. Las CIS solo han recibido cierta atención en la literatura desde una perspectiva jurídica, surgiendo algunos estudios sobre su naturaleza regulatoria y alcance normativo (Prieto, 2001; Díaz de la Rosa, 2006; Argudo, 2007; Rodríguez y Ortega, 2008; Rodríguez 2015), así como sus peculiaridades de carácter administrativo y fiscal (Arnáez-Arce y Atxabal-Rada, 2013). Por otra parte, algunos informes han tratado de cuantificar las CIS en España, aunque trabajando sobre estimaciones que no permiten ofrecer una imagen detallada y rigurosa de la situación de este sector (COCETA, 2010).

En base a esta discusión, el objetivo de esta investigación consiste en ofrecer una primera aproximación para conocer las principales características de las CIS en España. En concreto, estudiamos el contexto y proceso de institucionalización en el que surgen las CIS en España, el marco normativo que las regula en cada comunidad autónoma, la cuantificación del número de CIS existentes en España y su distribución geográfica, sus características organizativas y económicas básicas y, finalmente, se compara la evolución de estas entidades con el sector cooperativo total y las cooperativas de trabajo asociado en particular. Para ello se diseñó una investigación sobre el conjunto de CIS activas en el año 2017, basándonos en los datos cedidos por los distintos Registros autonómicos y provinciales de cooperativas, así como en las estadísticas sobre Economía Social publicadas anualmente por el Ministerio de Trabajo, Migraciones y Seguridad Social.

El estudio tiene dos fortalezas principales: Por un lado, es la primera investigación que delimita y cuantifica con datos oficiales las CIS en España, visibilizando una fórmula organizacional de la Economía Social española ampliamente desconocida hasta ahora en el ámbito académico. Por otro lado, este trabajo completa la caracterización del universo de las empresas sociales en España, respondiendo a los recientes llamamientos de diversos autores en la literatura científica internacional de empresa social sobre la necesidad de abandonar los excesos teóricos y centrarse en mapear empíricamente los distintos modelos de empresa social y contrastarlos con las conceptualizaciones existentes (entre otros, Pestoff y Hulgård, 2016; Defourny y Nyssens, 2017b).

El artículo se estructura de la siguiente manera. El siguiente apartado presenta el marco teóricoconceptual del trabajo, contextualizando las CIS en la literatura académica internacional sobre empresa social. El tercer apartado detalla la metodología y datos empleados en la investigación. Los siguientes apartados reportan los resultados del estudio, abordando en este orden el marco normativo de las CIS en España, las características básicas de estas organizaciones y su evolución en comparación con el conjunto del 
sector cooperativo. El último apartado recoge las conclusiones del trabajo, las contribuciones a la literatura, las limitaciones del estudio y posibles líneas de investigación futura.

\section{Marco conceptual: La Cooperativa de Iniciativa Social española en el contexto internacional de la empresa social}

El concepto de empresa social es objeto de un amplio debate en el terreno académico, sin existir hasta ahora consenso (Galera y Borzaga, 2009; Defourny y Nyssens, 2017b). Ello se debe, en primer lugar, a la naturaleza multidimensional del concepto de empresa social, que abarca distintas características o criterios como el perfil específico y el papel de los emprendedores sociales individuales, el lugar de la innovación, la búsqueda de ingresos de mercado en organizaciones sin fines de lucro, la asignación de beneficios para el cumplimiento de la misión social, y la gobernanza para un equilibrio sostenible entre los objetivos económicos y sociales (Borzaga y Defourny, 2001; Díaz-Foncea y Marcuello, 2012).

Un segundo aspecto clave es que la etiqueta de "empresa social" ha sido vinculada a una serie de fenómenos muy diversos como, por ejemplo, las estrategias de ingresos obtenidos por organizaciones sin fines de lucro, organizaciones voluntarias que prestan servicios públicos, organizaciones controladas democráticamente que combinan objetivos sociales y económicos, empresas con fines de lucro que operan en el ámbito del bienestar social y público, o empresas comunitarias que abordan problemas sociales de diversa índole (Teasdale, 2012). Asimismo, las empresas sociales pueden adoptar una amplia variedad de estructuras jurídicas y formas organizativas a lo largo del mundo (Defourny y Nyssens, 2010).

Finalmente, también ha influido el hecho de que, como sostienen algunos autores (Dey y Steyaert, 2012; Teasdale, 2012), en la construcción del concepto de empresa social confluyen discursos e intereses contrapuestos, así como lenguajes y narrativas divergentes provenientes de una amplia gama de actores. Como destaca sucintamente Teasdale (2012), la empresa social 'es un concepto fluido y controvertido, construido por diferentes actores que promueven discursos diferentes conectados a diferentes formas organizativas y que se basan en diferentes teorías académicas' (p. 99).

La literatura ha distinguido dos grandes conceptualizaciones para clasificar la naturaleza y dinámicas de las empresas sociales en el mundo: el enfoque anglosajón y el enfoque europeo (para un análisis detallado de estos enfoques, pueden consultarse los trabajos de Kerlin, 2006 y de Defourny y Nyssens, 2010).

En la tradición anglosajona, la empresa social constituye un concepto más amplio al referirse básicamente a las actividades económicas orientadas al mercado que sirven a un objetivo social, pudiendo ser realizadas por cualquier organización o empresa independientemente de su forma jurídica y el sector de la economía en el que actúa (Dees y Anderson, 2006; Kerlin, 2006). Así, esta conceptualización se centra en los propósitos externos de la organización en lugar de en sus dinámicas internas, es decir, en lo que hace una organización en lugar de en cómo lo hace (Teasdale, 2012). De hecho, el enfoque anglosajón relaciona en mayor medida la empresa social con un emprendedor social individual y tiende a focalizarse en la estrategia innovadora y el perfil particular del emprendedor social (Spear, 2006; Díaz-Foncea y Marcuello, 2012).

En cambio, en el enfoque europeo, la conceptualización de la empresa social es más estrecha. Bajo este enfoque, la empresa social se vincula con una unidad organizacional o empresa concreta, se destaca la naturaleza colectiva del emprendimiento social y se atiende en mayor medida a la gobernanza y, por tanto, a las dinámicas internas de la empresa (Díaz-Foncea y Marcuello, 2012; Pestoff y Hulgard, 2016). Esta conceptualización deriva en gran medida de las tradiciones colectivas de la economía social presentes en cooperativas, mutuas y asociaciones a lo largo de Europa (Defourny y Nyssens, 2010).

La red internacional EMES ha sido clave en el desarrollo de un enfoque común para el estudio de la empresa social en Europa (Borzaga y Defourny, 2001; Galera y Borzaga, 2009), considerando tres dimensiones claves en estas organizaciones: la dimensión económica, la dimensión social y la dimensión política o de gobernanza participativa (Defourny y Nyssens, 2017a; Pestoff y Hulgard, 2016). Ello contrasta con el enfoque unidimensional dominante, que tiende a situar a las empresas sociales a lo largo de un continuo que va desde un polo puramente social a uno puramente comercial, y que asume que las dimensiones sociales y comerciales son independientes e involucran una relación de suma cero, es decir, 'más de una, implica menos de la otra' (Pestoff y Hulgard, 2016: 1752).

A partir de la intersección entre las dimensiones mencionadas, los distintos principios de interés de las organizaciones (interés general, interés mutuo e interés de capital) y los distintos tipos de recursos en los que se basan las empresas sociales (recursos de mercado, recursos híbridos y recursos de no mercado), Defourny y Nyssens (2017b) distinguen cuatro grandes tipologías internacionales de empresa social: (i) el modelo de organización empresarial sin ánimo de lucro; (ii) el modelo de empresa social del sector público; (iii) el modelo de negocio social; y (iv) el modelo de cooperativa social. De acuerdo con Defourny y Nissens 
(2017b), el modelo de cooperativa social sigue una trayectoria que surge del Interés Mutuo y se aproxima al Interés General utilizando recursos híbridos provenientes del ámbito de mercado y no lucrativo.

No obstante, reconocen que estos grandes modelos se concretan en experiencias y formas socioeconómicas muy diversas, ya que las experiencias de emprendimiento social están fuertemente sujetas a las trayectorias institucionales y culturales propias de cada territorio en el que surgen. Por ello, los autores inciden en la necesidad de comenzar a contrastar empíricamente las conceptualizaciones existentes con la amplia variedad de empresas sociales que existen en el mundo para avanzar nuestro conocimiento en este campo de investigación emergente.

En el caso concreto de España, se han distinguido principalmente tres formas legales y organizacionales de empresa social: las empresas de inserción, los centros especiales de empleo y las cooperativas de iniciativa social (Spear et al., 2009; Díaz-Foncea y Marcuello, 2012). Como se señalaba anteriormente, los dos primeros modelos han sido ampliamente estudiados, especialmente en los campos de la economía social, el emprendimiento social y la innovación social. Sin embargo, las cooperativas de iniciativa social apenas han recibido atención académica en España. Estas últimas se entroncan en el modelo de cooperativa social identificado por Defourny y Nyssens, (2017b), que se extiende por varios países de Europa, siendo ejemplos pioneros las sociedades cooperativas de interés colectivo francesas (Lindsay y Hems, 2004) y las cooperativas sociales italianas (Thomas, 2004; Borzaga et al., 2017; García Jiménez y Strano, 2018).

Las diferencias entre las cooperativas convencionales y las cooperativas sociales son importantes. Las cooperativas convencionales son fundamentalmente empresas de interés mutual que son propiedad de sus miembros, quienes gestionan democráticamente la empresa. Es decir, estas organizaciones están enfocadas hacia el beneficio e intereses (de carácter no capitalista) de sus miembros (Bretos y Marcuello, 2017). El modelo de cooperativa social dota a las clases de cooperativas convencionales de un nuevo enfoque, incorporando el interés general a través de la búsqueda de beneficios para la sociedad en su conjunto o para un grupo objetivo específico, dando respuesta habitualmente a necesidades sociales insatisfechas en ámbitos como la asistencia social, la integración laboral o la protección del medio ambiente (Etxezarreta et al., 2018). De hecho, las cooperativas sociales generalmente integran limitaciones en el reparto de beneficios entre los socios. En el caso concreto de España, la ley estatal de Cooperativas marca una limitación del 100\% para las CIS. Como organizaciones cooperativas, las CIS basan sus formas de gobierno en el poder igualitario y democrático. Ello deriva fundamentalmente del hecho de que las decisiones en la Asamblea General se toman bajo la regla "una persona, un voto". Adicionalmente, las cooperativas sociales tienden a integrar en la toma de decisiones a diferentes grupos de interés como trabajadores, voluntarios o usuarios (Herrero, 2015).

La investigación presentada en este artículo pretende arrojar luz sobre el proceso de institucionalización y principales características de la Cooperativa de Iniciativa Social española. A continuación, se detalla la metodología y datos empleados para ello.

\section{Metodología y datos}

El objetivo de la investigación consiste en ofrecer una primera aproximación para conocer el surgimiento y naturaleza de las CIS, una forma organizacional de la Economía Social en España apenas estudiada en el ámbito científico. Para ello, se recogieron datos acerca del conjunto de CIS activas en España en el año 2017, identificándose en concreto un total de 647 organizaciones que conforman nuestra muestra (véase la Tabla 1). Dichos datos se obtuvieron principalmente de los Registros autonómicos y provinciales de cooperativas, tras el envío de una solicitud formal y la posterior comunicación por contacto telefónico. La información facilitada comprende el nombre de la cooperativa, el CIF, el año de fundación de la cooperativa, el número inicial de socios, el capital social inicial, el sector de actividad y código CNAE, el domicilio social, el número de teléfono y otros datos de contacto disponibles. Por otro lado, se consultaron y analizaron las referencias a las CIS contenidas tanto en la legislación estatal como en las legislaciones autonómicas de cooperativas. 
Tabla. 1. Distribución geográfica de las CIS activas en España en 2017.

\begin{tabular}{|c|c|c|c|c|c|c|c|c|c|}
\hline $\begin{array}{l}\text { Comunidad } \\
\text { Autónoma }\end{array}$ & $\begin{array}{c}\text { Cooperativas } \\
\text { de Iniciativa } \\
\text { Social }\end{array}$ & $\begin{array}{c}\text { Cooperativas } \\
\text { de Iniciativa } \\
\text { Social de } \\
\text { Trabajo } \\
\text { Asociado }\end{array}$ & $\begin{array}{c}\text { Cooperativas } \\
\text { de } \\
\text { Integración } \\
\text { Social }\end{array}$ & $\begin{array}{c}\text { Cooperativas } \\
\text { de Bienestar } \\
\text { Social }\end{array}$ & $\begin{array}{l}\text { Cooperativas } \\
\text { de Interés } \\
\text { Social }\end{array}$ & $\begin{array}{l}\text { Cooperativ } \\
\text { as de } \\
\text { Inserción } \\
\text { Social }\end{array}$ & $\begin{array}{l}\text { Cooperativ } \\
\text { as de } \\
\text { Utilidad } \\
\text { Pública }\end{array}$ & $\begin{array}{l}\text { Cooperativ } \\
\text { as sin } \\
\text { ánimo de } \\
\text { lucro }\end{array}$ & $\begin{array}{c}\text { Total } \\
\text { Cooperativ } \\
\text { as Sociales }\end{array}$ \\
\hline Andalucía & & & & & 132 & & & & 132 \\
\hline Aragón & & 25 & & & & & & & 25 \\
\hline Asturias & 6 & & 1 & & & & & & 7 \\
\hline Baleares & 12 & & & & & 0 & & & 12 \\
\hline Canarias & 0 & & & & & & & & 0 \\
\hline Cantabria & 0 & & 0 & & & & & & 0 \\
\hline $\begin{array}{l}\text { Castilla La } \\
\text { Mancha }\end{array}$ & 10 & & 3 & & & & & & 13 \\
\hline Castilla León & 29 & & & & & & & & 29 \\
\hline Cataluña * & 144 & & & & & & & & 144 \\
\hline Extremadura & & & & 0 & & & & & 0 \\
\hline Galicia & & & 2 & & & & & & 2 \\
\hline Madrid & 80 & & 13 & & & & & & 93 \\
\hline Murcia & 9 & 0 & & & & & & & 9 \\
\hline Navarra & 7 & & & & & & & & 7 \\
\hline País Vasco & 62 & & 0 & & & & 79 & & 141 \\
\hline La Rioja & & 5 & 0 & & & & & & 5 \\
\hline $\begin{array}{l}\text { Comunidad } \\
\text { Valenciana }\end{array}$ & & & 25 & & & & 0 & 0 & 25 \\
\hline $\begin{array}{l}\text { Registro } \\
\text { Central }\end{array}$ & 3 & & & & & & & & 3 \\
\hline Total & 362 & 30 & 44 & 0 & 132 & 0 & 79 & 0 & 647 \\
\hline
\end{tabular}

Fuente: elaboración propia.

* Los datos de Cataluña corresponden a las cooperativas asociadas a la Federación de Cooperativas de Cataluña.

Asimismo, también se realiza un análisis comparativo sobre la situación de las CIS dentro del sector cooperativo en su conjunto y, en concreto, con las cooperativas de trabajo asociado. Dicho análisis comparativo comprende la evolución temporal, la distribución geográfica y sectorial, y el tamaño de estas organizaciones. Las cifras sobre el conjunto de cooperativas y de las cooperativas de trabajo asociado en España se han obtenido de las estadísticas sobre economía social del Ministerio de Trabajo, Migraciones y Seguridad Social (MITRAMISS).

Debe señalarse que en los casos de la Comunidad de Madrid y la Comunidad Valenciana no ha sido posible obtener datos del número inicial de socios y/o de capital social inicial en las CIS y, por tanto, no quedan recogidos en los resultados. En el caso de Cataluña, debido a las dificultades que presentaba la información en el Registro de Cooperativas, sólo se ha podido obtener datos sobre las CIS asociadas a la Federación de Cooperativas. Por tanto, los datos corresponden a las CIS federadas, en vez de al conjunto total realmente registradas. Por otro lado, en el caso del País Vasco, una cooperativa puede ser doblemente calificada como Cooperativa de Iniciativa Social y Cooperativa de Utilidad Pública, habiéndose eliminado las duplicidades encontradas.

Durante el proceso de recogida de datos, observamos rápidamente la necesidad de ampliar el concepto de "Cooperativa de Iniciativa Social" que marca la ley estatal de cooperativas para abarcar el conjunto de denominaciones con que las legislaciones autonómicas se refieren a este tipo de organizaciones (véase una relación de las distintas denominaciones en la Tabla 2). En cualquier caso, por una cuestión de simplicidad, en esta investigación englobamos a todas estas denominaciones bajo el paraguas de "Cooperativa Social" (CIS).

\section{Marco normativo de las Cooperativas de Iniciativa Social en España}

Las CIS forman un grupo heterogéneo de organizaciones que tienen como marco normativo general la Ley 27/1999, de 16 de julio, de Cooperativas. Esta ley nacional reconoce 12 tipos de cooperativas (de trabajadores, consumidores, agrícolas, vivienda, explotación común de la tierra, servicios, pescadores, transporte de trabajadores, seguro, salud, educación y crédito), que pueden obtener la calificación de "cooperativa de iniciativa social". El artículo 106 de dicha Ley las define como: 
“aquellas cooperativas que, sin ánimo de lucro y con independencia de su clase, tienen por objeto social, bien la prestación de servicios asistenciales mediante la realización de actividades sanitarias, educativas, culturales u otras de naturaleza social, o bien el desarrollo de cualquier actividad económica que tenga por finalidad la integración laboral de personas que sufran cualquier clase de exclusión social y, en general, la satisfacción de necesidades sociales no atendidas por el mercado".

Asimismo, la práctica totalidad de las comunidades autónomas ha desarrollado su propia normativa sobre cooperativas, a excepción de la comunidad autónoma de Canarias. Mientras algunas leyes autonómicas se adhieren a la nomenclatura de cooperativa de iniciativa social utilizada en la ley estatal, en las normativas de otras comunidades autónomas se emplean denominaciones similares como cooperativas de integración social, cooperativas de inserción social o cooperativas de interés social (véase la Tabla 2).

En primer lugar, se agrupan las comunidades autónomas que regulan la calificación de Cooperativa de Iniciativa Social de manera igual o similar a las características descritas en la ley estatal. Se observa que en Canarias, Castilla-León, Cataluña, Navarra, Murcia, Madrid y País Vasco se incluye la cooperativa de iniciativa social con un carácter más general y engloba diferentes modalidades, distintos tipos de servicios y actividades económicas, tanto para la prestación de servicios asistenciales como para los servicios de integración laboral. Además, describe la cooperativa de iniciativa social como una entidad sin ánimo de lucro y no hay condiciones para el tipo y número de socios.

En segundo lugar, también con la calificación de Cooperativa de Iniciativa Social, se agrupan las comunidades de Asturias, Baleares, Cantabria y Castilla La Mancha y Extremadura. En este grupo se indica que la principal actividad es la prestación de servicios asistenciales, se mantiene la condición de que estas organizaciones sean sin ánimo de lucro y no se especifican requisitos especiales para para el tipo y número de socios. En este grupo hay que incluir también a la Comunidad Valenciana con la calificación de Cooperativas no lucrativas, ya que tienen las mismas características que las mencionadas anteriormente.

El tercer grupo lo forman La Rioja y Aragón, que delimitan las cooperativas de iniciativa social a las de Trabajo Asociado. En el caso de La Rioja, se especifica los colectivos de población a las que se dirigen los servicios y se refieren a servicios de protección relacionados con dichos colectivos. En el caso de Aragón, se amplían los servicios al desarrollo de actividades empresariales de carácter asistencial educativo, de prevención y de integración o inserción.

El cuarto grupo de comunidades autónomas son las que utilizan el término Cooperativas de Integración Social. En este caso encontramos a Asturias, Cantabria, Castilla La Mancha, Extremadura, Madrid, La Rioja y la Comunidad Valenciana. Bajo esta denominación se incluyen las cooperativas que tienen como finalidad la integración de colectivos con problemas de inserción social o laboral, que exclusivamente son sin ánimo de lucro y están constituidas mayoritariamente por personas pertenecientes a dichos colectivos. En el caso de Cantabria, se hace una especial referencia a las cooperativas de consumo calificadas de Integración Social, mientras que Madrid, además de las de consumidores, lo amplía a las de trabajo asociado y cooperativas integrales. Asimismo, en País Vasco, la legislación señala que las Cooperativas de Integración Social estarán constituidas, al menos mayoritariamente, por disminuidos físicos o psíquicos y dedicadas a la prestación de todo tipo de servicios, sin delimitar expresamente si tienen ánimo de lucro o no.

En quinto lugar, Baleares regula las Cooperativas de Inserción Social de forma que, igual que en el caso anterior, la finalidad es la integración de colectivos con problemas de inserción social, obligando a que sean sin ánimo de lucro, aunque no hay condiciones para el tipo de cooperativas y el número de socios.

Tabla. 2. Marco normativo autonómico de las Cooperativas de Iniciativa Social.

\begin{tabular}{|l|l|l|l|}
\hline $\begin{array}{c}\text { Comunidad } \\
\text { Autónoma }\end{array}$ & Año & \multicolumn{1}{|c|}{ Ley } & \multicolumn{1}{|c|}{ Denominación básica } \\
\hline Andalucía & 2011 & Ley 14/2011, de 23 de diciembre, de Sociedades Cooperativas Andaluzas. & $\begin{array}{l}\text { Cooperativas de interés } \\
\text { social }\end{array}$ \\
\hline Aragón & 2014 & $\begin{array}{l}\text { Ley 9/1998, de 22 de diciembre, de Cooperativas de Aragón } \\
\text { Decreto Legislativo 2/2014, de 29 de agosto, del Gobierno de Aragón, por } \\
\text { el que se aprueba el texto refundido de la Ley de Cooperativas de Aragón. }\end{array}$ & $\begin{array}{l}\text { Cooperativas (de trabajo) de } \\
\text { iniciativa social }\end{array}$ \\
\hline Asturias & 2010 & $\begin{array}{l}\text { Ley 4/2010, de 29 de junio, de Cooperativas. Comunidad Autónoma del } \\
\text { Principado de Asturias }\end{array}$ & $\begin{array}{l}\text { Cooperativas de iniciativa } \\
\text { social / Cooperativas de } \\
\text { integración social }\end{array}$ \\
\hline Baleares & 2003 & $\begin{array}{l}\text { Ley 1/2003, de 20 de marzo, de cooperativas de Baleares (BOIB 42, de } \\
\text { 29/03/2003 y BOE 91, de 16/04/2003). } \\
\text { Ley 5/2011, de 31 de marzo, de modificación de la ley 1/2003, de 20 de } \\
\text { marzo, de cooperativas de las Illes Balears }\end{array}$ & $\begin{array}{l}\text { Cooperativas de iniciativa } \\
\text { social / Cooperativas de } \\
\text { inserción social }\end{array}$ \\
\hline Canarias & 1999 & $\begin{array}{l}\text { Ley 27/1999, de 16 de julio, de Cooperativas (estatal) } \\
\text { Cooperativas de iniciativa }\end{array}$ \\
\hline
\end{tabular}




\begin{tabular}{|c|c|c|c|}
\hline Cantabria & 2013 & Ley 6/2013, de 6 de noviembre, de Cooperativas de Cantabria & $\begin{array}{l}\text { Cooperativas de iniciativa } \\
\text { social / Cooperativas de } \\
\text { integración social }\end{array}$ \\
\hline $\begin{array}{l}\text { Castilla La } \\
\text { Mancha }\end{array}$ & 2010 & Ley 11/2010, de 4 de noviembre, de Cooperativas de Castilla-La Mancha & $\begin{array}{l}\text { Cooperativas de iniciativa } \\
\text { social / Cooperativas de } \\
\text { integración social }\end{array}$ \\
\hline $\begin{array}{l}\text { Castilla y } \\
\text { León }\end{array}$ & 2011 & $\begin{array}{l}\text { Ley 4/2002, de } 11 \text { de abril, de Cooperativas de la Comunidad de Castilla y } \\
\text { León } \\
\text { Ley } 6 / 2011 \text {, de } 4 \text { de noviembre, por la que se modifica la Ley 4/2002, de } 11 \\
\text { de abril, de Cooperativas de Castilla y León }\end{array}$ & $\begin{array}{l}\text { Cooperativas de iniciativa } \\
\text { social }\end{array}$ \\
\hline Cataluña & 2015 & $\begin{array}{l}\text { Ley } 12 / 2015 \text {, de } 9 \text { de julio, de cooperativas. Comunidad Autónoma de } \\
\text { Cataluña }\end{array}$ & $\begin{array}{l}\text { Cooperativas de iniciativa } \\
\text { social }\end{array}$ \\
\hline Extremadura & 2011 & Ley $9 / 2018$, de 30 de octubre, de sociedades cooperativas de Extremadura & $\begin{array}{l}\text { Cooperativas de iniciativa } \\
\text { social / Cooperativas de } \\
\text { integración social / } \\
\text { Cooperativas sin ánimo de } \\
\text { lucro }\end{array}$ \\
\hline Galicia & 2011 & $\begin{array}{l}\text { Ley } 6 / 2016 \text {, de } 4 \text { de mayo, de la economía social de Galicia } \\
\text { Ley } 5 / 1998 \text {, de } 18 \text { de diciembre, de Cooperativas de Galicia } \\
\text { Ley } 14 / 2011 \text {, de } 16 \text { de diciembre, por la que se modifica la Ley } 5 / 1998 \text {, de } \\
18 \text { de diciembre, de Cooperativas de Galicia }\end{array}$ & $\begin{array}{l}\text { Cooperativas de integración } \\
\text { social }\end{array}$ \\
\hline Madrid & 1999 & Ley 4/1999, de 30 de marzo, de Cooperativas de la Comunidad de Madrid & $\begin{array}{l}\text { Cooperativas de iniciativa } \\
\text { social / Cooperativas de } \\
\text { integración social }\end{array}$ \\
\hline Murcia & 2006 & $\begin{array}{l}\text { Ley } 8 / 2006 \text {, de } 16 \text { de noviembre, de Sociedades Cooperativas de la Región } \\
\text { de Murcia }\end{array}$ & $\begin{array}{l}\text { Cooperativas de iniciativa } \\
\text { social }\end{array}$ \\
\hline Navarra & $\begin{array}{l}1996 \\
/ \\
2006\end{array}$ & $\begin{array}{l}\text { Ley Foral 12/1996, de } 2 \text { de julio, de Cooperativas de Navarra } \\
\text { Ley Foral 5/2006, de } 11 \text { de abril, de modificación de la Ley 12/1996, de } 2 \\
\text { de julio, de Cooperativas de Navarra, para la adición de la regulación de las } \\
\text { cooperativas de iniciativa social } \\
\text { Ley Foral 2/2015, de } 22 \text { de enero, de microcooperativas de trabajo asociado. }\end{array}$ & $\begin{array}{l}\text { Cooperativas de iniciativa } \\
\text { social }\end{array}$ \\
\hline País Vasco & 2006 & $\begin{array}{l}\text { Ley 4/1993, de } 24 \text { de junio, de Cooperativas de Euskadi (B.O.P.V. de } 19 \text { de } \\
\text { julio) } \\
\text { Ley } 1 / 2000 \text {, de } 29 \text { de junio, de modificación de la Ley de Cooperativas de } \\
\text { Euskadi (BOE 14-11-2011). } \\
\text { Ley 8/2006, de } 1 \text { de diciembre, de segunda modificación de la Ley de } \\
\text { Cooperativas de Euskadi (BOE 13-12-2011). }\end{array}$ & $\begin{array}{l}\text { Cooperativas de iniciativa } \\
\text { social / Cooperativas de } \\
\text { integración social / } \\
\text { Cooperativas de utilidad } \\
\text { pública }\end{array}$ \\
\hline La Rioja & 2001 & Ley 4/2001, de 2 de julio, de Cooperativas de La Rioja & $\begin{array}{l}\text { Cooperativas (de trabajo) de } \\
\text { iniciativa social / } \\
\text { Cooperativas de integración } \\
\text { social }\end{array}$ \\
\hline $\begin{array}{l}\text { Comunidad } \\
\text { Valenciana }\end{array}$ & 2015 & $\begin{array}{l}\text { Decreto Legislativo } 2 / 2015 \text {, de } 15 \text { de mayo, del Consell, por el que aprueba } \\
\text { el texto refundido de la Ley de Cooperativas de la Comunitat Valenciana } \\
\text { (Vigente desde } 21 / 05 / 2015 \text { ). } \\
\text { Ley } 4 / 2014 \text {, de } 11 \text { de julio, de modificación de la Ley } 8 / 2003 \text {, de } 24 \text { de } \\
\text { marzo, de la Generalitat, de Cooperativas de la Comunitat Valenciana } \\
\text { (Derogada desde } 21 / 05 / 2015 \text { ). }\end{array}$ & $\begin{array}{l}\text { Cooperativas de integración } \\
\text { social / Cooperativas de } \\
\text { utilidad pública / } \\
\text { Cooperativas sin ánimo de } \\
\text { lucro }\end{array}$ \\
\hline
\end{tabular}

Fuente: elaboración propia.

En sexto lugar, Andalucía incluye las Cooperativas de Interés Social como aquellas que tienen como finalidad la promoción y plena integración sociolaboral de determinados colectivos, tampoco delimita expresamente si son con o sin ánimo de lucro, y estas tienen que estar constituidas al menos mayoritariamente, por disminuidos físicos o psíquicos.

\section{Características básicas de las Cooperativas de Iniciativa Social en España}

A continuación se realiza un análisis descriptivo de las CIS a través de las siguientes características: evolución temporal de las CIS en España, su distribución geográfica por comunidad autónoma, su tamaño en 
términos de número inicial de socios y capital social inicial, y su distribución sectorial. Estos elementos permiten delimitar un perfil básico de la CIS española.

\subsection{Evolución temporal de las Cooperativas de Iniciativa Social}

En cuanto a la evolución temporal, el Gráfico 1 muestra el año de creación de las CIS inscritas en 2017 en los Registros de Cooperativas, desde 1969 hasta 2017. Lo primero que llama la atención es que existan CIS anteriores a 1999, año en el que esta calificación aparece por primera vez en la legislación cooperativa estatal. Cabe entender, en estos casos, que estas cooperativas existían antes del desarrollo legislativo (antes de 1999 ya existían cooperativas en servicios social y/o educación, entre otros) y que solicitan la calificación cuando ésta aparece en la Ley, manteniendo en los Registros de Cooperativas el año de fundación.

Gráfico. 1. Creación de CIS por años (1975 - 2017).

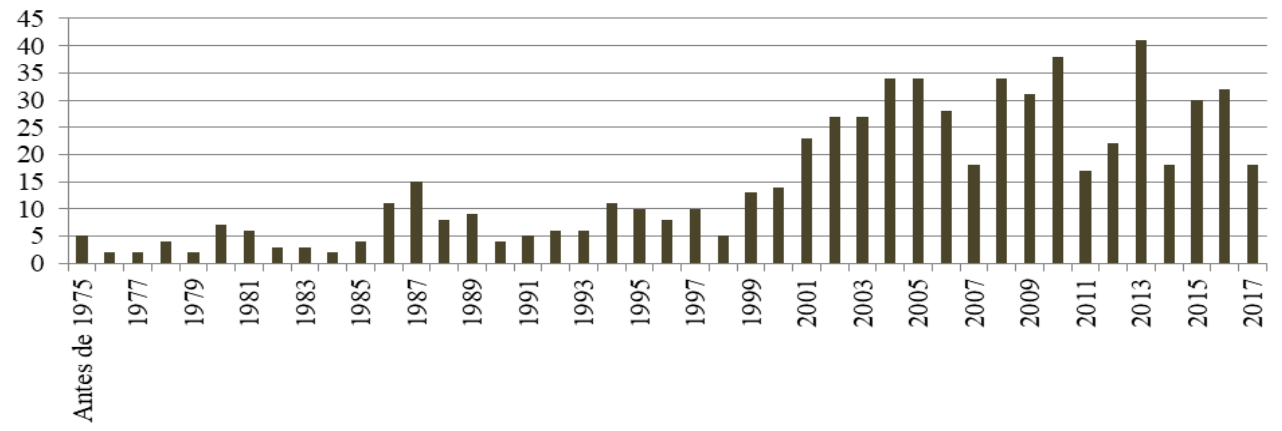

Fuente: elaboración propia

Se observa un importante crecimiento en la creación de CIS a partir de 1999. Anteriormente, el número de CIS creadas al año se situaba entre 5 y 10 desde 1985, con la excepción de 1987 que alcanza las 15 CIS creadas. A partir del año 2000, en cambio, las cifras de creación superan las 20 CIS, llegando en 2004, 2005 y 2008 a las 34 CIS creadas. En este sentido, con algún altibajo, la tendencia de creación es creciente hasta 2013, que alcanza el máximo de nivel con 41 CIS creadas. Si bien existe una cierta tendencia de ralentización en la creación de CIS desde 2013, cabe señalar que todas CIS creadas desde entonces siguen manteniendo su actividad durante los años siguientes. En términos generales, la tendencia general de crecimiento en el volumen de CIS puede deberse, como señala Arroyo (2017), a la reducción de los servicios a las personas desde las Administraciones Públicas, erigiéndose las CIS como una herramienta para llenar ese vacío y atender esas necesidades sociales.

\subsection{Distribución geográfica de las Cooperativas de Iniciativa Social}

Las CIS en España se localizan de forma amplia en todo el territorio nacional, aunque tienen especial presencia en algunas Comunidades Autónomas. En el Mapa 1 se observa la correspondencia entre las comunidades más pobladas y con mayor desarrollo económico con la concentración de CIS. En concreto, las CIS parecen localizarse en Andalucía, así como a lo largo del eje mediterráneo, con una alta presencia en Cataluña. Asimismo, Madrid y País Vasco también concentran un alto volumen de CIS en su territorio. Estos territorios son particularmente relevantes, ya que son los que ostentan algunos de los sectores cooperativos más sólidos en España (Bretos y Morandeira 2016). 
Mapa 1. Ubicación territorial de las CIS en España.

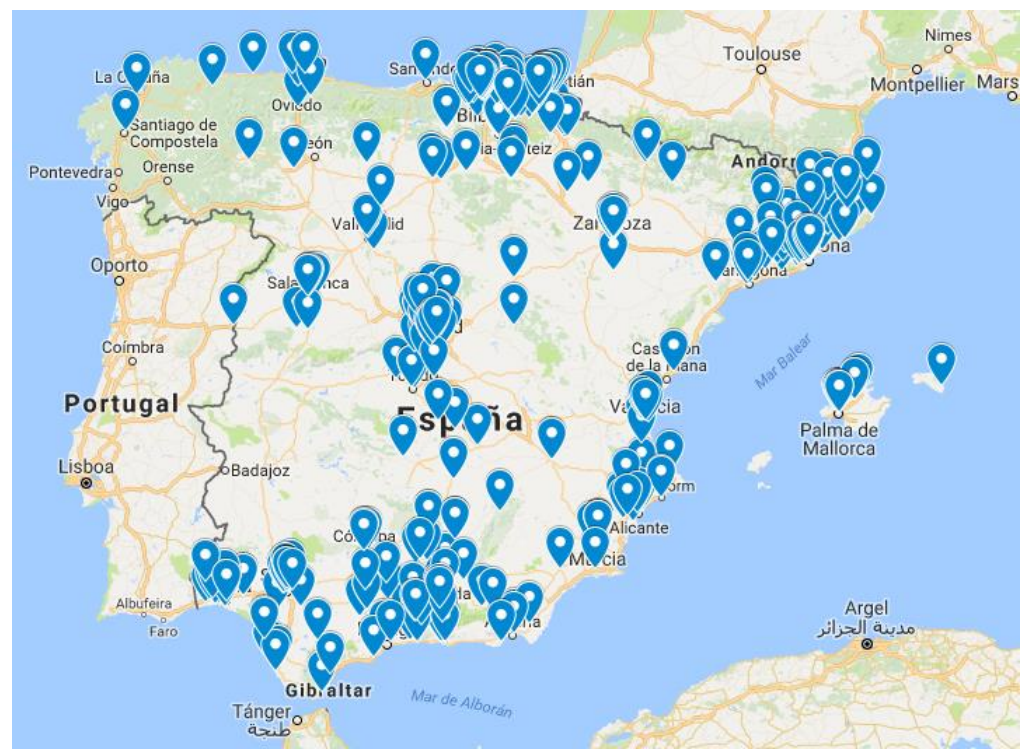

Fuente: elaboración propia con la herramienta Google Maps

El Gráfico 2 aporta datos sobre la realidad de las CIS por territorio. En este sentido, se observa que Cataluña, junto con País Vasco, son los territorios con más CIS, frente a Canarias, Cantabria y Extremadura, que no tienen activa ninguna CIS en su territorio. Entre ambos extremos, se observan 4 escalones de presencia de las CIS en España: en el primero estarían incluidas Andalucía, junto a Cataluña y País Vasco, con un volumen superior al 20\% (de hecho, estas tres comunidades agrupan al 65\% de las CIS en España). En un segundo escalón estaría la Comunidad de Madrid, que agrupa el 14\% de las CIS en España (cerca del centenar de CIS, en valor absoluto), un alto porcentaje que queda algo por detrás de los tres primeros territorios. En el tercer escalón se incluirían Aragón, Castilla y León, y Comunidad Valenciana, con porcentajes alrededor del $4 \%$ (entre 25 y 30 CIS, en valor absoluto). Finalmente, estarían aquellos territorios en los que, aun habiéndose creado alguna CIS, tienen una representación inferior al $2 \%$ en España (no alcanzan las 15 CIS en valor absoluto): Asturias, Baleares, Castilla La Macha, Murcia, Navarra, La Rioja y Galicia.

Gráfico. 2. Distribución de las CIS en España, por Comunidad Autónomas (2017).

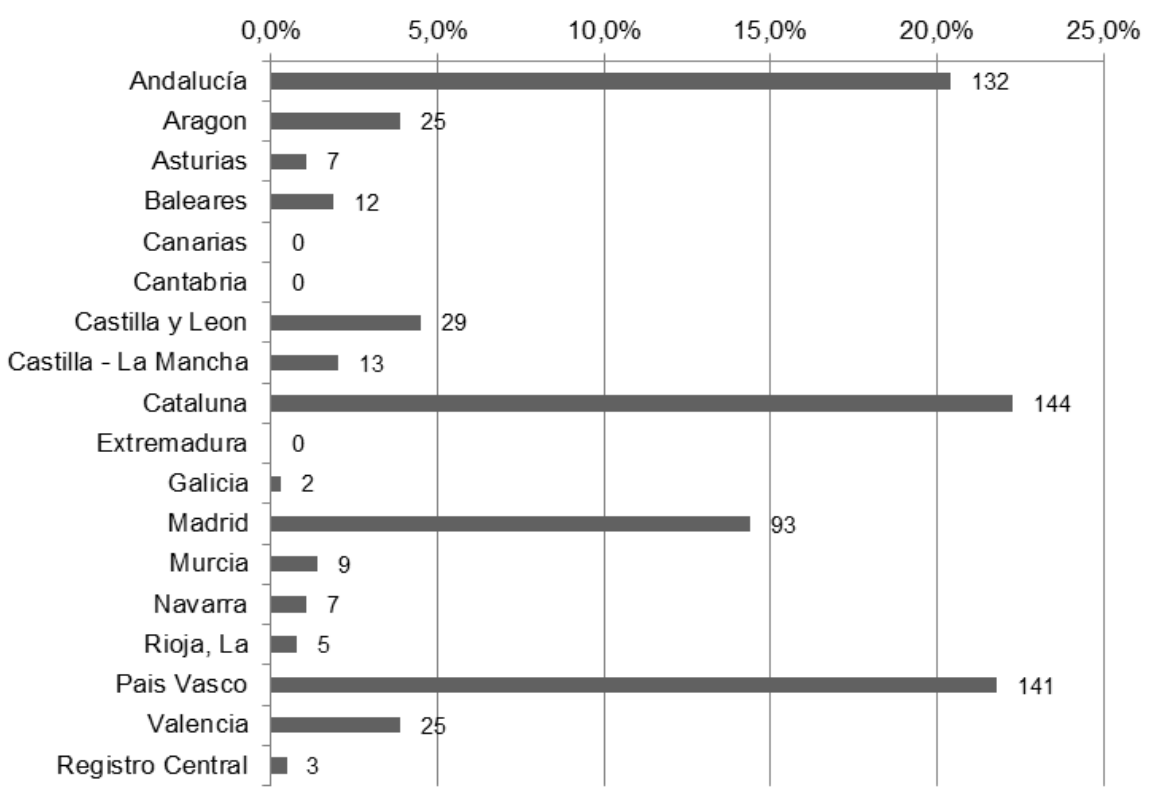

Fuente: elaboración propia 
De esta manera, se observa un mayor dinamismo y promoción de este modelo de cooperativa en unos determinados territorios, en los que se utiliza esta fórmula de forma más habitual. Por el contrario, cabe destacar las tres en las que ninguna cooperativa ha apostado por una calificación como CIS. Cabe destacar el caso de Extremadura y Cantabria, en las que existe una legislación cooperativa autonómica que innova con la calificación de las cooperativas sociales (con sendas denominaciones: Cooperativa de Bienestar Social y Cooperativa de Integración Social, respectivamente), pero que no aplica a la realidad de las cooperativas del territorio, al no existir ninguna con esta calificación. Queda pendiente responder si esta innovación ha sido la causa de que no existan CIS en este territorio o, por el contrario, servirá para facilitar el desarrollo de este modelo cooperativo.

\subsection{Distribución sectorial de las Cooperativas de Iniciativa Social}

En cuanto a la distribución por sectores económicos de las CIS españolas, en el Gráfico 3 se puede apreciar que las actividades económicas principales son el ámbito educativo (200 CIS) y el de servicios sociales (192 CIS), suponiendo ambos alrededor del $30 \%$ del total de CIS en España. No obstante, hay que señalar que el sector de Servicios Sociales ha sido dividido en tres (Actividades sanitarias, Actividades en establecimientos residenciales, y Servicios sociales) para ofrecer información más detallada sobre las actividades específicas realizadas. Arroyo (2010) estima las CIS agrupando las cooperativas incluidas en el epígrafe Q.- Actividades sanitarias y de servicios sociales de la Clasificación Nacional de Actividades Económicas (CNAE). Utilizando este método se comprueba que es el sector más relevante entre las CIS con el 37\% del total de entidades existentes en España, alcanzando las 239 CIS.

Gráfico. 3. Distribución sectorial de las CIS en España (2017).

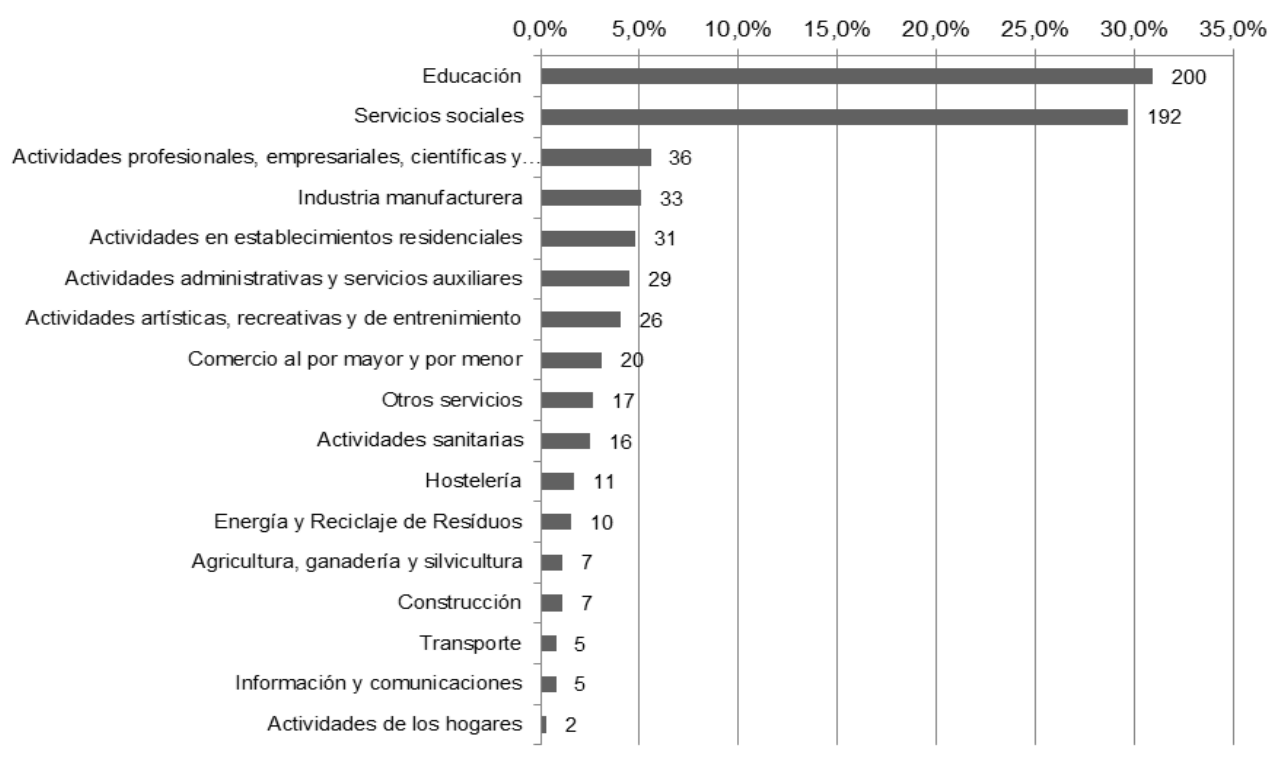

Fuente: elaboración propia

Es asimismo reseñable que existen CIS en 15 de los 20 epígrafes (75\%) en los que divide la CNAE los sectores económicos de las empresas. Los cinco sectores en los que las CIS no están presentes son las B.Industrias extractivas, K.- Actividades financieras y de seguros, L.- Actividades inmobiliarias, O.Administración Pública y defensa, y U.- Actividades de organizaciones y organismos extraterritoriales.

En el resto de epígrafes hay al menos una CIS presente. De hecho, hay CIS tanto en el sector primario, dedicándose principalmente al cultivo de hortalizas, raíces y tubérculos $(1,1 \%)$, como en el secundario (industria), establecidos en actividades tan diversas como artes gráficas o investigación y desarrollo (7,7\%), así como en el sector servicios, en toda su extensión (más del 90\%).

Se pueden establecer cuatro grupos de actividades, en función de su relevancia entre las CIS:

- $\quad$ El primer grupo, de forma destacada, como se ha señalado, serían Educación y Servicios Sociales.

- Un segundo grupo lo conformarían aquellas actividades en las que se ubican entre 4\% y el 5,5\% de las CIS (alrededor de 30 entidades): Actividades profesionales, empresariales, científicas y técnicas, Industria manufacturera, Actividades en establecimientos residenciales, Actividades administrativas y servicios auxiliares, y Actividades artísticas, recreativas y de entretenimiento. 
El tercero estaría formado por aquellas actividades que representan entre el 1,5\% y el 3,5\% de entidades (de 10 a 20 CIS): Comercio al por mayor y por menor, Otros servicios, Actividades sanitarias, Hostelería, y Energía y Reciclaje de Residuos.

Finalmente, el cuarto grupo está constituido por aquellas actividades más minoritarias (agrupa a menos del 1\% de las CIS): Agricultura, ganadería y silvicultura, Construcción, Transporte, Información y comunicaciones, y Actividades de los hogares.

\subsection{Tamaño de las Cooperativas de Iniciativa Social}

La caracterización de las CIS existentes en España se completa con la descripción del tamaño inicial de estas organizaciones, basado tanto en el número de socios inicial como en el capital social aportado estatutariamente para iniciar la actividad. No se han podido obtener los datos actualizados sobre el tamaño real de estas organizaciones, ya que los Registros de cooperativas no disponen de esta información, al solo incluir los datos del momento de constitución.

En cuanto al número de socios, la Tabla 3 permite observar que el 70\% de las CIS creadas en el periodo de estudio tuvieron 5 o menos socios iniciales. Llama la atención que más de la mitad de estas entidades ha sido creada por 3 personas, el número mínimo de socios establecido en la legislación con carácter general. Además, existen 16 CIS creadas con 2 trabajadores a través de la modalidad de "pequeña cooperativa" que algunas legislaciones de cooperativas han comenzado a introducir.

Asimismo, asumiendo cierta asimilación entre socios iniciales y trabajadores, se podría establecer que casi el $80 \%$ de las CIS podrían ser clasificadas como pequeñas empresas (menos de 10 personas) y el $90 \%$ de las mismas como PYMES (al tener menor de 50 personas). De esta manera, se puede concluir que las CIS nacen con un tamaño pequeño.

No obstante, cabe destacar que existen dos CIS que fueron inscritas con más de 1.000 socios iniciales, y otras dos, por encima de los 500 socios iniciales. Estas cuatro cooperativas corresponden al sector Educación, se entiende que agrupando a familias socias de los centros de formación que gestionan. Además, las cuatro están ubicadas en el País Vasco, en concreto, en Guipúzcoa.

Tabla. 3. Tamaño inicial de las CIS, por número de socios.

\begin{tabular}{|c|c|c|}
\hline Tamaño Socios & Número de CIS & $\begin{array}{c}\text { Porcentaje sobre el } \\
\text { total }\end{array}$ \\
\hline $0-5$ & 322 & $69,50 \%$ \\
\hline $6-10$ & 79 & $17,10 \%$ \\
\hline $11-25$ & 32 & $6,90 \%$ \\
\hline $26-50$ & 14 & $3,00 \%$ \\
\hline $51-100$ & 4 & $0,90 \%$ \\
\hline $101-250$ & 5 & $1,10 \%$ \\
\hline $251-500$ & 3 & $0,60 \%$ \\
\hline $501-1.000$ & 2 & $0,40 \%$ \\
\hline Más de 1.000 & 2 & $0,40 \%$ \\
\hline
\end{tabular}

Fuente: elaboración propia

Por otro lado, en cuanto al tamaño basado en el capital inicial (Tabla 4), cabe destacar que suele estar entre los 3.000 y los 5.000 euros, donde se agrupan el 35\% de las CIS. Esta cantidad es el mínimo legal de las Sociedades Limitadas y suele servir de referencia para otras formas jurídicas como las cooperativas. Por encima y por debajo, otros dos tramos suelen agrupar a la mayoría CIS: en un sentido, el $16 \%$ se agrupan entre 1.000 y 2.000 euros, y en otro, el $20 \%$ están entre 10.000 y 50.000 euros. Estos datos permiten concluir que las CIS no nacen excesivamente capitalizadas. 
Tabla. 4. Tamaño inicial de las CIS, por capital social aportado.

\begin{tabular}{|c|c|c|}
\hline Capital Social (euros) & Número de CIS & $\begin{array}{c}\text { Porcentaje sobre } \\
\text { el total }\end{array}$ \\
\hline $0-1.000 €$ & 39 & $7,40 \%$ \\
\hline $1.001-2.000 €$ & 86 & $16,40 \%$ \\
\hline $2.001-3.000 €$ & 28 & $5,30 \%$ \\
\hline $3.001-5.000 €$ & 184 & $35,10 \%$ \\
\hline $5.001-10.000 €$ & 42 & $8,00 \%$ \\
\hline $10.001-50.000 €$ & 102 & $19,50 \%$ \\
\hline $50.001-100.000 €$ & 19 & $3,60 \%$ \\
\hline $100.001-250.000 €$ & 7 & $1,30 \%$ \\
\hline $250.001-500.000 €$ & 5 & $1,00 \%$ \\
\hline $500.001-1.000 .000 €$ & 7 & $1,30 \%$ \\
\hline $1.000 .001-10.000 .000 €$ & 3 & $0,60 \%$ \\
\hline $10.000 .001-50.000 .000 €$ & 1 & $0,20 \%$ \\
\hline Más de $50.000 .000 €$ & 1 & $0,20 \%$ \\
\hline
\end{tabular}

Fuente: elaboración propia

Asimismo, destacar por el otro lado, la existencia de dos CIS que tienen un capital inicial por encima de los 10 millones de euros, y una de ellas, por encima de los 50 millones de euros. Esta última corresponde a una CIS dedicada al ámbito de la investigación, el desarrollo, la innovación tecnológica y la difusión científica. En cambio, la primera se ubica en el sector educativo. Ambas están localizadas en el País Vasco.

\section{Análisis comparado de las CIS con el sector cooperativo total y las cooperativas de trabajo asociado}

Tras el estudio de las características básicas de las CIS en España, cabe contextualizar su situación dentro del sector cooperativo. Para ello, se analiza a continuación la evolución temporal, la distribución geográfica y sectorial, y el tamaño de estas organizaciones, en comparación con el conjunto de las cooperativas en España, y en concreto, con las cooperativas de trabajo asociado. Ello permite observar si la situación de las CIS corresponde al conjunto del sector o, en cambio, mantienen una dinámica específica que debe ser analizada de forma separada.

\subsection{Evolución temporal comparada}

En el Gráfico 4 se presenta la evolución de las CIS, de las cooperativas en general (COOP) y de las de trabajo asociado (CTA) en particular, desde 1999 (año de entrada de las CIS en la legislación nacional) hasta 2016 (último año disponible para las CTA y las COOP en las estadísticas del Ministerio de Trabajo, Migraciones y Seguridad Social).

Gráfico. 4. Evolución de las CIS comparada con el sector cooperativo (1999-2016).

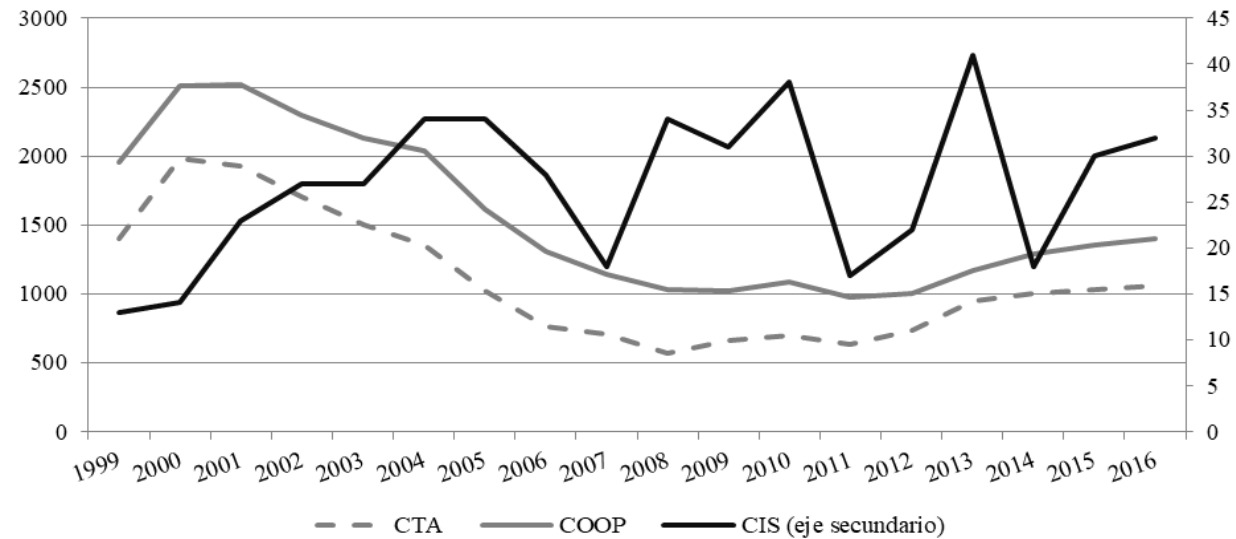

Fuente: elaboración propia 
Con la cautela derivada del hecho de que existe un reducido volumen relativo de CIS, en el gráfico se puede apreciar que las CIS tienen una dinámica de creación de entidades diferente a la que mantienen las CTA y las cooperativas en general. Se observan 3 etapas en el periodo: hasta 2004 el número de CIS creadas se incrementa, mientras que el resto del sector cooperativo muestra una tendencia decreciente desde 2001. Posteriormente, entre 2005 y 2007 muestra una tendencia decreciente, que se mantiene con altibajos muy señalados hasta 2015, cuando las CIS parecen recuperar las tasas de creación, al igual que el resto del sector cooperativo. Llama la atención los altibajos en la creación de CIS en 2008, 2010 y 2013, que no siguen la tendencia del resto del sector y hacen plantear esta diferente dinámica.

\subsection{Distribución geográfica comparada}

La Tabla 5 presenta la distribución regional de cooperativas activas en las distintas tipologías analizadas. En ella cabe atender más al peso relativo que supone en cada región cada uno de los modelos.

Tabla 5. Distribución geográfica comparada con el sector cooperativo (2016).

\begin{tabular}{|l|l|l|l|l|l|l|}
\hline \multicolumn{1}{|c|}{$\begin{array}{c}\text { Comunidad } \\
\text { Autónoma }\end{array}$} & \multicolumn{1}{|c|}{ COOP } & \multicolumn{1}{c|}{$\%$ COOP } & \multicolumn{1}{|c|}{ CTA } & \multicolumn{1}{c|}{ CTA } & \multicolumn{1}{c|}{$\%$ CIS } \\
\hline Andalucía & 2.710 & $23 \%$ & 1699 & $25 \%$ & 132 & $20 \%$ \\
\hline Aragón & 423 & $4 \%$ & 171 & $3 \%$ & 25 & $4 \%$ \\
\hline Asturias & 168 & $1 \%$ & 108 & $2 \%$ & 7 & $1 \%$ \\
\hline Baleares & 110 & $1 \%$ & 68 & $1 \%$ & 12 & $2 \%$ \\
\hline Canarias & 202 & $2 \%$ & 89 & $1 \%$ & - & $0 \%$ \\
\hline Cantabria & 57 & $0 \%$ & 43 & $1 \%$ & - & $0 \%$ \\
\hline $\begin{array}{l}\text { Castilla La } \\
\text { Mancha }\end{array}$ & 853 & $7 \%$ & 291 & $4 \%$ & 13 & $2 \%$ \\
\hline Castilla y León & 949 & $8 \%$ & 241 & $4 \%$ & 29 & $5 \%$ \\
\hline Cataluña & 1.538 & $13 \%$ & 982 & $15 \%$ & 144 & $22 \%$ \\
\hline $\begin{array}{l}\text { Comunidad } \\
\text { Valenciana }\end{array}$ & 1.260 & $10 \%$ & 720 & $11 \%$ & 25 & $4 \%$ \\
\hline Extremadura & 512 & $4 \%$ & 164 & $2 \%$ & - & $0 \%$ \\
\hline Galicia & 566 & $5 \%$ & 290 & $4 \%$ & 2 & $0 \%$ \\
\hline Madrid & 599 & $5 \%$ & 343 & $5 \%$ & 93 & $14 \%$ \\
\hline Murcia & 775 & $6 \%$ & 601 & $9 \%$ & 9 & $1 \%$ \\
\hline Navarra & 223 & $2 \%$ & 91 & $1 \%$ & 7 & $1 \%$ \\
\hline País Vasco & 996 & $8 \%$ & 730 & $11 \%$ & 141 & $22 \%$ \\
\hline La Rioja & 81 & $1 \%$ & 32 & $0 \%$ & 5 & $1 \%$ \\
\hline
\end{tabular}

Fuente: elaboración propia

Se observa que existen distintos comportamientos en función de los territorios. Por un lado, País Vasco, Cataluña y Madrid representan territorios en los que las CIS tienen un mayor peso que el sector cooperativo en general: un $12 \%$ más de peso en el caso del País Vasco, y un $9 \%$ de media en el caso de Cataluña y Madrid. Por otro lado, la Comunidad Valenciana y Murcia mantienen un peso menor de las CIS en comparación con el resto de las cooperativas y las CTA (7\% y 6\%, respectivamente).

Por detrás de estos dos territorios, se sitúan Andalucía, Castilla La Mancha y Galicia, en las que se puede apreciar alrededor de un $4 \%$ más de peso de las cooperativas en general que en el caso de las CIS. Finalmente, Navarra, Castilla y León y Asturias tienen un peso muy similar, muy reducido (1\%) en todos ellos. No se incluye en el análisis los tres territorios sin CIS al no poder comparar los datos existentes en cada caso.

En resumen, País Vasco aparece como un territorio con una presencia destacable de CIS en comparación con el peso que supone sobre el total del sector cooperativo, seguido de Cataluña y Madrid. En cambio, la Comunidad Valenciana y Murcia muestran un peso de las CIS menor al que les correspondería por el peso del sector cooperativo regionales sobre el volumen nacional. 
Tabla. 6. Peso de las CIS en el Sector Cooperativo, por comunidad autónoma (2016).

\begin{tabular}{|l|c|}
\hline Comunidad Autónoma & Porcentaje \\
\hline Andalucía & $5 \%$ \\
\hline Aragón & $6 \%$ \\
\hline Asturias & $4 \%$ \\
\hline Baleares & $11 \%$ \\
\hline Castilla La Mancha & $2 \%$ \\
\hline Castilla y León & $3 \%$ \\
\hline Cataluña & $9 \%$ \\
\hline Comunidad Valenciana & $2 \%$ \\
\hline Galicia & $0 \%$ \\
\hline Madrid & $16 \%$ \\
\hline Murcia & $1 \%$ \\
\hline Navarra & $3 \%$ \\
\hline País Vasco & $14 \%$ \\
\hline La Rioja & $6 \%$ \\
\hline
\end{tabular}

Fuente: elaboración propia

Por otro lado, la Tabla 6 muestra el peso de las CIS sobre el total de cooperativas por comunidad autónoma. En ella se observa que Madrid (16\%) y País Vasco (14\%) son los territorios en los que las CIS suponen un mayor porcentaje del sector cooperativo. A estos se añade las Islas Baleares, donde las CIS también tienen un importante peso (11\%), aunque este territorio no tenga una alta presencia en el total de CIS ni en el sector cooperativo. En el lado contrario, en regiones como Galicia (0\%), Murcia (1\%), Comunidad Valenciana (2\%), Castilla y León (3\%) o Navarra (3\%), las CIS no tienen una presencia relevante en el conjunto del sector cooperativo de la región.

\subsection{Distribución sectorial comparada}

La Tabla 7 presenta el peso de cada actividad económica sobre el volumen total de cada tipología de cooperativa analizada. En ella destacan las actividades de Educación y de Servicios Sociales y Sanitarias, donde las CIS destacan sobre el resto del sector cooperativo (18\% y $31 \%$ de mayor peso de las CIS, respectivamente). De esta manera, las CIS muestran una concentración importante en ambos sectores.

Tabla. 7. Distribución sectorial comparada de las CIS con el sector cooperativo (2016).

\begin{tabular}{|l|c|c|c|c|c|c|}
\hline & COOP & $\%$ COOP & CTA & $\%$ CTA & CIS & $\%$ CIS \\
\hline $\begin{array}{l}\text { Agricultura, ganadería y } \\
\text { silvicultura }\end{array}$ & 2.458 & $14 \%$ & 428 & $4 \%$ & 8 & $1 \%$ \\
\hline Industria Extractiva & 12 & $0 \%$ & 11 & $0 \%$ & - & $0 \%$ \\
\hline Industria Manufacturera & 3.078 & $18 \%$ & 1.613 & $17 \%$ & 32 & $5 \%$ \\
\hline Energía y Residuos & 118 & $1 \%$ & 37 & $0 \%$ & 10 & $2 \%$ \\
\hline Construcción & 888 & $5 \%$ & 834 & $9 \%$ & 7 & $1 \%$ \\
\hline $\begin{array}{l}\text { Comercio al por mayor y el } \\
\text { por menor }\end{array}$ & 3.312 & $19 \%$ & 1.495 & $16 \%$ & 20 & $3 \%$ \\
\hline Transporte & 1.308 & $8 \%$ & 543 & $6 \%$ & 5 & $1 \%$ \\
\hline Hostelería & 233 & $1 \%$ & 571 & $6 \%$ & 11 & $2 \%$ \\
\hline Información y Comunicación & 247 & $1 \%$ & 212 & $2 \%$ & 5 & $1 \%$ \\
\hline Actividades Financieras & 304 & $2 \%$ & 29 & $0 \%$ & - & $0 \%$ \\
\hline Actividad Inmobiliaria & 53 & $0 \%$ & 37 & $0 \%$ & - & $0 \%$ \\
\hline $\begin{array}{l}\text { Actividades Profesionales, } \\
\text { Empresariales y Técnicas }\end{array}$ & 897 & $5 \%$ & 742 & $8 \%$ & 36 & $6 \%$ \\
\hline Actividades Administrativas & 738 & $4 \%$ & 534 & $6 \%$ & 29 & $4 \%$ \\
\hline Administración Pública & 6 & $0 \%$ & 4 & $0 \%$ & - & $0 \%$ \\
\hline
\end{tabular}




\begin{tabular}{|l|c|c|c|c|c|c|} 
Educación & 2.039 & $12 \%$ & 1.371 & $14 \%$ & 200 & $31 \%$ \\
\hline Sanidad y Servicios Sociales & 754 & $4 \%$ & 671 & $7 \%$ & 239 & $37 \%$ \\
\hline $\begin{array}{l}\text { Actividades Artísticas y de } \\
\text { entretenimiento }\end{array}$ & 262 & $2 \%$ & 230 & $2 \%$ & 26 & $4 \%$ \\
\hline Otros servicios & 378 & $2 \%$ & 271 & $3 \%$ & 17 & $3 \%$ \\
\hline Actividades de los Hogares & 12 & $0 \%$ & 1 & $0 \%$ & 2 & $0 \%$ \\
\hline
\end{tabular}

Fuente: elaboración propia

Además, se observan dos bloques de actividades diferenciadas en función del tipo de cooperativa que prevalece en cada actividad: por un lado, el correspondiente al de Energía y Residuos, y Actividades Artísticas y de Entretenimiento, en las que, junto con Educación y Servicios Sociales y Sanitarios, las CIS tienen una presencia mayor que otras cooperativas. En otros sectores, el conjunto de cooperativas tienen un peso significativamente mayor que las CIS. Estos son el Comercio al por mayor y por menor (14\% de más peso del conjunto del sector que en las CIS), Industria Manufacturera (12\%), Agricultura (8\%) y Construcción (6\%) y Transporte (6\%). En las actividades de Construcción, Hostelería y Actividades profesionales, empresariales y técnicas, las CTA tienen una mayor concentración que las CIS o el conjunto del sector cooperativo.

Tabla. 8. Peso de las CIS en el Sector Cooperativo, por sector de actividad (2016).

\begin{tabular}{|l|c|}
\hline \multicolumn{1}{|c|}{ Sector de actividad } & Porcentaje \\
\hline Agricultura, ganadería y silvicultura & $0 \%$ \\
\hline Industria Extractiva & $0 \%$ \\
\hline Industria Manufacturera & $1 \%$ \\
\hline Energía y Residuos & $8 \%$ \\
\hline Construcción & $1 \%$ \\
\hline Comercio al por mayor y el por menor & $1 \%$ \\
\hline Transporte & $0 \%$ \\
\hline Hostelería & $5 \%$ \\
\hline Información y Comunicación & $2 \%$ \\
\hline $\begin{array}{l}\text { Actividades Profesionales, Empresariales y } \\
\text { Técnicas }\end{array}$ & $4 \%$ \\
\hline Actividades Administrativas & $4 \%$ \\
\hline Educación & $10 \%$ \\
\hline Sanidad y Servicios Sociales & $32 \%$ \\
\hline Actividades Artísticas y de entretenimiento & $10 \%$ \\
\hline Otros servicios & $4 \%$ \\
\hline Actividades de los Hogares & $17 \%$ \\
\hline
\end{tabular}

Fuente: elaboración propia

La Tabla 8 muestra el peso de las CIS sobre el sector cooperativo en cada sector de actividad. La actividad donde las CIS tienen una mayor representación es en los Servicios Sociales y las Actividades Sanitarias (32\%), es decir, en este sector el 32\% de las cooperativas seleccionan esta tipología para desarrollar su actividad. Asimismo, las CIS también son la fórmula elegida por las cooperativas en actividades como "Actividades de los Hogares como empleadores de personal doméstico" (17\%), Educación (10\%), Actividades Artísticas y de entretenimiento (10\%) y Energía y Residuos (8\%). En este último sector económico las CIS están principalmente enfocadas hacia el reciclaje y la recuperación de residuos a través de la inserción socio-laboral de personas en riesgo de exclusión.

\subsection{Tamaño comparado}

La Tabla 9 presenta la distribución de las cooperativas en función del tamaño. Cabe señalar que el tamaño en el caso de las CTA y las cooperativas en general se calcula para las cooperativas activas existentes en 2016, 
mientras que, en el caso de las CIS, estos datos atienden al tamaño inicial de estas entidades (calculada con los socios iniciales). Por tanto, esta información no captura las tendencias de crecimiento o decrecimiento en el número de socios que hayan podido experimentar las CIS desde su nacimiento.

Tabla. 9. Tamaño de las CIS, comparado con el sector cooperativo.

\begin{tabular}{|l|c|c|c|c|c|c|}
\hline $\begin{array}{c}\text { Socios } \\
\text { iniciales }\end{array}$ & COOP & $\%$ COOP & CTA & \% CTA & CIS & \% CIS \\
\hline $0-5$ & 7334 & $61 \%$ & 4328 & $65 \%$ & 322 & $70 \%$ \\
\hline $6-10$ & 1891 & $16 \%$ & 1071 & $16 \%$ & 79 & $17 \%$ \\
\hline $11-25$ & 1515 & $13 \%$ & 742 & $11 \%$ & 32 & $7 \%$ \\
\hline $26-50$ & 628 & $5 \%$ & 283 & $4 \%$ & 14 & $3 \%$ \\
\hline $51-100$ & 339 & $3 \%$ & 148 & $2 \%$ & 4 & $1 \%$ \\
\hline $101-250$ & 208 & $2 \%$ & 73 & $1 \%$ & 5 & $1 \%$ \\
\hline Mayor 250 & 123 & $1 \%$ & 32 & $0 \%$ & 7 & $2 \%$ \\
\hline
\end{tabular}

Fuente: elaboración propia

Se observa que, en todos los casos, las cooperativas tienen un tamaño pequeño (más del $80 \%$ tienen menos de 10 trabajadores), siendo mayoritaria la escala por debajo de los 5 trabajadores. En el caso de las CIS, esta distribución es incluso más pronunciada, pues hay un $10 \%$ más de entidades entre 0 y 5 trabajadores que en el conjunto del sector cooperativo. En el caso del siguiente tramo (entre 6 y 10 trabajadores) los porcentajes son similares. En el extremo opuesto, destaca que existe un mayor porcentaje de CIS con más de 250 trabajadores en comparación con el sector cooperativo. De hecho, es el tramo de más de 250 trabajadores en el que las CIS suponen un mayor peso sobre el total del sector.

\section{Conclusiones}

El objetivo de este artículo residía en ofrecer una primera aproximación para conocer las cooperativas sociales en España. Para ello, se ha presentado su proceso de institucionalización y marco normativo, sus características básicas en términos de número de entidades, tamaño, actividad económica, etc., y su diferente comportamiento y evolución frente al sector cooperativo en su conjunto y las cooperativas de trabajo asociado en particular.

A finales de 2017, en España existían un total de 647 CIS activas. Estas entidades se crean sobre todo a partir de 1999 con su reconocimiento institucional en la ley estatal de cooperativas, si bien previamente ya existían algunas cooperativas dedicadas a servicios de carácter social y comunitario. Hasta 2013, se observa una tendencia generalizada ascendente, con dinámicas importantes de creación de CIS también en años centrales de la crisis económica. Sin embargo, desde entonces se observan altibajos en la creación de estas entidades. Es también reseñable el pequeño tamaño con que se crean estas entidades. El $87 \%$ de las CIS se crean con un número menor de 10 socios iniciales. Asimismo, las CIS no nacen excesivamente capitalizadas. El 35\% de las CIS se crea con un capital social inicial de entre 3.000 y 5.000 euros, el $16 \%$ se agrupan entre 1.000 y 2.000 euros, mientras que el $20 \%$ lo hacen con un capital de entre 10.000 y 50.000 euros.

En cuanto a la distribución geográfica de las CIS en España, se observa que las comunidades autónomas de Andalucía, Cataluña, País Vasco y Madrid concentran el mayor número de entidades. De hecho, alrededor del $80 \%$ del total de CIS se localizan en estos territorios. Por el contrario, en Extremadura, Cantabria y Canarias no existía ninguna CIS activa a fecha de elaboración de la investigación. Respecto a la actividad económica, destaca que existen CIS operando bajo 15 de los 20 epígrafes en los que divide la CNAE los sectores económicos de las empresas. No obstante, buena parte de las CIS españolas desarrollan su actividad en los sectores de Educación y de Servicios sociales, ya que cada uno aglutina alrededor del $30 \%$ del total de entidades existente.

Por su parte, el análisis comparativo de las CIS con el sector cooperativo arroja algunas diferencias significativas. Cabe destacar que en País Vasco, Cataluña y Madrid las CIS tienen una mayor importancia relativa en comparación con otros territorios, mientras que en Comunidad Valenciana y Murcia sucede lo contrario. También es significativo que las CIS tienden a crearse con un tamaño menor que las cooperativas en su conjunto, ya que el tramo de 0 a 5 socios iniciales es incluso más pronunciado en este tipo de cooperativas. Por último, es reseñable que las CIS tienen una mayor importancia relativa en los sectores de Educación, Servicios sociales y sanitarios, Energía y residuos, y Actividades artísticas y de entretenimiento, 
mientras que las cooperativas convencionales tienen un peso mayor en los sectores de Comercio al por mayor y por menor, Industria manufacturera, Agricultura, Construcción y Transporte.

El artículo contribuye en dos direcciones a la literatura. Por un lado, realiza una aportación a la literatura española sobre economía social, ya que las cooperativas sociales apenas han sido analizadas en la literatura académica. En este sentido, este estudio delimita, cuantifica y caracteriza las cooperativas sociales en España a partir de datos oficiales de los propios Registros de Cooperativas. Además, mientras que las escasas aportaciones científicas hasta la fecha procedían del ámbito jurídico (por ejemplo, Argudo, 2007; Rodríguez, 2015), este trabajo ofrece una perspectiva de carácter más económico y organizacional sobre las CIS.

Por otro lado, el trabajo contribuye a la literatura internacional sobre empresa social, abordando recientes llamamientos de diversos autores (entre otros, Pestoff y Hulgård, 2016; Defourny y Nyssens, 2017b) que han sugerido la necesidad de comenzar a contrastar empíricamente las conceptualizaciones existentes de empresa social con la amplia variedad de modelos y experiencias que existen en distintos territorios. En este sentido, el perfil obtenido para las CIS encaja perfectamente en la conceptualización europea de empresa social propuesta por diversos autores próximos a la red internacional EMES, al combinar una dimensión económica, social y de gobernanza democrática (por ejemplo, Defourny y Nyssens, 2017a; Galera y Borzaga, 2009; Pestoff y Hulgard, 2016). Como hemos visto, las CIS españolas aúnan una actividad económica y una misión social, al operar fundamentalmente en sectores orientados al interés general, como son la educación y los servicios de carácter social y sanitario. Además, estas entidades se estructuran en torno una gobernanza democrática en la que trabajadores, usuarios y otros stakeholders participan activamente en la toma de decisiones. Por tanto, el estudio se sitúa en una línea incipiente de investigaciones empíricas que han mapeado y analizado comparativamente el surgimiento, desarrollo y características de distintas tipologías de empresa social en distintas regiones y países del mundo (entre otros, Abbou et al., 2017; Borzaga et al., 2017; Barraket et al., 2017; Bidet et al., 2018).

La investigación también tiene relevancia en el ámbito de la política pública. Como señala Wilkinson (2015), para diseñar políticas públicas eficientes de apoyo a la empresa social y al emprendimiento social, es fundamental mapear los distintos modelos de empresa social en Europa y profundizar en la comprensión de los ecosistemas en que surgen y se desarrollan, así como sus características concretas. En este contexto, la investigación contribuye igualmente a la consecución del objetivo marcado por la "Iniciativa a favor de la Empresa Social", relativo a incrementar la visibilidad del emprendimiento social, y más concretamente a través de las siguientes acciones contempladas en dicho objetivo: Acción 5 (identificar las mejores prácticas mediante el establecimiento de un registro exhaustivo de empresas sociales en Europa) y Acción 7 (ayudar a los gobiernos nacionales y regionales a introducir medidas para apoyar, promover y financiar empresas sociales) (Comisión Europea, 2011).

Finalmente, debe señalarse que el análisis descriptivo presentado supone únicamente una primera aproximación a la comprensión de las CIS como modelo de empresa social paradigmático en España. Las CIS conforman un laboratorio extraordinario para avanzar nuestro conocimiento en diferentes líneas de investigación claves en el ámbito de la empresa social, tales como las interacciones entre las dimensiones económica, social y de gobernanza participativa (Pestoff y Hulgard, 2016), la generación de distintos tipos de valor social (Etxezarreta et al., 2018), la importancia de los partenariados de organizaciones de economía social con otras empresas privadas y públicas para abordar grandes retos sociales y medioambientales (Defourny y Nyssens, 2017b), los desafíos de estabilidad y gobernanza que envuelven dichos acuerdos (Nicholls y Huybrechts, 2016), las estrategias de crecimiento y expansión las potencialidades y contradicciones que puede implicar el crecimiento organizacional en estas empresas (Bretos et al., 2019), el diseño e implementación de políticas formales de gestión de recursos humanos (Bastida et al., 2018), o las tensiones derivadas de tener que equilibrar, por un lado, requisitos asociados a la competencia en el mercado, y demandas asociadas a la provisión de bienestar social, por el otro (Bretos et al., 2018c). Estas y otras cuestiones resultan claves para avanzar en nuestra comprensión del presente y de la futura evolución de las empresas cooperativas y sociales (Ben-ner, 2018).

\section{Referencias bibliográficas}

Abbou, I. Gidron, B., Buber-Ben David, N. et al. (2017) Social enterprise in Israel: The swinging pendulum between collectivism and individualism. Social Enterprise Journal, No 13, Vol. 4, pp. 329-44.

Argudo, J. L. (2007) Las Cooperativas sin ánimo de lucro: ¿Vuelta a los orígenes o respuesta a nuevas necesidades sociales? Revista Vasca de Economía Social, No 3, pp. 179-201.

Arnáez-Arce, V.M., y Atxabal-Rada, A. (2014) Las cooperativas de utilidad pública e iniciativa social. Aspectos administrativos y fiscales. Boletín de la Asociación Internacional de Derecho Cooperativo, № 47, pp. 199-228. 
Arroyo, P. (2017) Las Cooperativas de trabajo de Iniciativa Social. Revista Española del Tercer Sector, No 35, pp. 151160.

Barraket, J., Douglas, H., Eversole, R., Mason, C., McNeill, J., Morgan, B. (2017) Classifying social enterprise models in Australia. Social Enterprise Journal, No 13, Vol. 4, pp. 345-61.

Bastida, R., Marimon, F., y Carreras, L. (2018) Human resource management practices and employee job satisfaction in nonprofit organizations. Annals of Public and Cooperative Economics, No 89, pp. 323-338.

Ben-Ner, A. (2018) Reflections on the Future Evolution of Social, Nonprofit and Cooperative Enterprise. Annals of Public and Cooperative Economics, № 89, Vol. 1, pp. 109-124.

Bidet, E., Eum, H., y Ryu, J. (2018) Diversity of Social Enterprise Models in South Korea. Voluntas: International Journal of Voluntary and Nonprofit Organizations, $\mathrm{N}^{\circ}$ 29, Vol. 6, pp. 1261-1273.

Borgaza, C., y Defourny, J. (2001) The emergence of social enterprise. New York: Routledge.

Borzaga, C., Poledrini, S., y Galera, G. (2017) Social Enterprise in Italy: Typology, diffusion and characteristics. Euricse Working Papers, $95 \mid 17$.

Bretos, I., y Moranderia, J. (2016) La Economía Social ante la actual crisis económica en la Comunidad Autónoma del País Vasco. REVESCO. Revista de Estudios Cooperativos, Tercer Cuatrimestre, No 122, pp. 7-33. DOI: 10.5209/rev_REVE.2016.v122.52020.

Bretos, I., y Marcuello, C. (2017) Revisiting globalization challenges and opportunities in the development of cooperatives. Annals of Public and Cooperative Economics, № 88, Vol. 1, pp. 47-73.

Bretos, I., Díaz-Foncea, M., Marcuello, C., y Marcuello, C. (2018) Cooperativas, capital social y emprendimiento: Una perspectiva teórica. REVESCO. Revista de Estudios Cooperativos, Segundo Cuatrimestre, No 128, pp. 76-98. DOI: http://dx.doi.org/10.5209/REVE.59775.

Bretos, I., Díaz-Foncea, M., y Marcuello, C. (2018) Cooperativas e internacionalización: Un análisis de las 300 mayores cooperativas del mundo. CIRIEC-España, Revista de Economía Pública, Social y Cooperativa, No 92, pp. 5-37.

Bretos, I., Errasti, A., y Marcuello, C. (2018) Ownership, governance and the diffusion of HRM practices in multinational worker cooperatives: Case-study evidence from the Mondragon group. Human Resource Management Journal, $\mathrm{N}^{\mathrm{o}} 28$, Vol. 1, pp. 76-91.

Bretos, I., Errasti, A., y Marcuello, C. (2019) Multinational expansion of worker cooperatives and their employment practices: Markets, institutions, and politics in Mondragon. ILR Review, No 72, Vol. 3, pp. 580-605.

Bull, M., y Ridley-Duff, R., (2019) Towards an appreciation of ethics in social enterprise business models. Journal of Business Ethics, No 159, Vol. 3, pp. 619-634.

Cabaleiro Casal, M.J., Iglesias Malvido, C., y Martínez Fontaíña, R. (2019) Democratic firms and economic success. The co-op model. REVESCO. Revista de Estudios Cooperativos, Tercer Cuatrimestre, No 132, pp. 29-45. DOI: http://dx.doi.org/10.5209/REVE.65482.

Chaves, R., y Monzón, J.L. (2018) La economía social ante los paradigmas económicos emergentes: innovación social, economía colaborativa, economía circular, responsabilidad social empresarial, economía del bien común, empresa social y economía solidaria. CIRIEC-España, Revista de Economía Pública, Social y Cooperativa, No 93, pp. 5-50.

Choi, N., y Majumdar, S. (2014) Social entrepreneurship as an essentially contested concept: Opening a new avenue for systematic future research. Journal of Business Venturing, $\mathrm{N}^{\circ} 29$, Vol. 3, pp. 363-376.

COCETA (2010) Cuando se trata de personas, las cooperativas llevan la iniciativa Cooperativas de trabajo de iniciativa social. Radiografía de un sector en evolución. Madrid: COCETA-Confederación Española de Cooperativas de Trabajo Asociado.

Comisión Europea (2011) Social Business Initiative: Creating a favourable climate for social enterprises, key stakeholders in the social economy and innovation. Bruselas.

Dacin, P.A., Dacin, M.T., y Tracey, P. (2011) Social entrepreneurship: A critique and future directions. Organization Science, $\mathrm{N}^{\mathrm{O}}$ 22, Vol. 5, pp. 1203-13.

Dees, J.G., y Anderson, B.B. (2006) Framing a Theory of Social Entrepreneurship: Building on Two Schools of Practice and Thought. ARNOVA occasional paper series, $\mathrm{N}^{\circ}$ 1, Vol. 3, pp. 39-66.

Defourny, J., y Nyssens, M. (2010) Conceptions of Social Enterprise and Social Entrepreneurship in Europe and the United States: Convergences and Differences. Journal of Social Entrepreneurship, № 1, Vol. 1, pp. 32-53.

Defourny, J., y Nyssens, M. (2017) Mapping Social Enterprise Models: Some Evidence from the 'ICSEM' Project. Social Enterprise Journal, № 13, Vol. 4, pp. 318-328.

Defourny, J., y Nyssens, M. (2017b) Fundamentals for an International Typology of Social Enterprise Models. Voluntas: International Journal of Voluntary and Nonprofit Organizations, No 28, Vol. 6, pp. 2469-97.

Dey, P., y Steyaert, C. (2012) Social entrepreneurship: Critique and the radical enactment of the social. Social Enterprise Journal, No 8, Vol. 2, pp. 90-107.

Díaz de la Rosa, A. (2006) Las cooperativas de iniciativa social. Anuario da Facultade de Dereito da Universidade de A Coruña, $\mathrm{N}^{\mathrm{o}} 10$, pp. 201-210.

Díaz-Foncea, M., y Marcuello, C. (2012) Social enterprises and social markets: models and new trends. Service business, $\mathrm{N}^{\mathrm{o}}$ 6, Vol. 1, pp. 61-83.

Díaz-Foncea, M., Marcuello, C., y Marcuello, Ch. (2012) Empresas sociales y evaluación del impacto social. CIRIECEspaña, Revista de Economía Pública, Social y Cooperativa, № 75, pp. 178-198.

Díaz-Foncea, M., y Marcuello, C. (2014) Las empresas sociales en España: concepto y características. Revista Vasca de Economía Social, No 8 , pp. 143-64.

Díaz-Foncea, M. (coord.) (2017) Social Enterprise in Spain: A Diversity of Roots and a Proposal of Models. ICSEM Working Papers, № 29. 
Etxezarreta, E., Mendiguren, J.C.P., Diaz, L., y Errasti, A. (2018) Valor social de las cooperativas sociales: Aplicación del modelo poliédrico en la cooperativa para la acogida de menores Zabalduz S.Coop. CIRIEC-España, Revista de Economía Pública, Social y Cooperativa, № 93, pp. 155-180.

Galera, G., y Borzaga, C. (2009) Social enterprise: An international overview of its conceptual evolution and legal implementation. Social Enterprise Journal, No 5, Vol. 3, pp. 210-228.

García Jiménez, M., y Strano, A. (2018) El cooperativismo social como respuesta a la crisis económica en el territorio calabrés. REVESCO. Revista de Estudios Cooperativos, Tercer Cuatrimestre, No 129, pp. 102-122. DOI: http://dx.doi.org/10.5209/REVE.62491.

Guzmán, C., Santos, F. J., y Barroso, M. O. (2019a) Analysing the links between cooperative principles, entrepreneurial orientation and performance. Small Business Economics, in press, DOI: 10.1007/s11187-019-00174-5.

Guzmán, C., Santos, F. J., Barroso, M. O. (2019b) Cooperative essence and entrepreneurial quality: A comparative contextual analysis. Annals of Public and Cooperative Economics, in press, DOI: 10.1111/apce.12257.

Herrero, M. (2015) Las empresas sociales: Un grupo en expansión en el ámbito de la Economía Social. Tesis Doctoral, Universitat de València.

Kerlin, J. A. (2006) Social enterprise in the United States and Europe: Understanding and learning from the differences. Voluntas: International Journal of Voluntary and Nonprofit Organizations, № 17, pp. $246-262$.

Kerlin, J.A. (2013) Defining social enterprise across different contexts a conceptual framework based on institutional factors. Nonprofit and Voluntary Sector Quarterly, No 42, Vol. 1, pp. 84-108.

Lindsay, G., y Hems, L. (2004) Sociétés Coopératives d'Intérêt Collectif: The Arrival of Social Enterprise within the French Social Economy. Voluntas: International Journal of Voluntary and Nonprofit Organizations, № 15, Vol. 3, pp. 265-86.

Nicholls, A., y Huybrechts, B. (2016) Sustaining inter-organizational relationships across institutional logics and power asymmetries: the case of fair trade. Journal of Business Ethics, $\mathrm{N}^{\circ} 135$, Vol. 4, pp. 699-714.

Pestoff, V., y Hulgard, L. (2016). Participatory governance in social enterprise. Voluntas: International Journal of Voluntary and Nonprofit Organizations, $\mathrm{N}^{\circ} 27$, Vol. 4, pp. 1742-1759

Prieto, J. A. (2001) La configuración de las cooperativas de iniciativa social como cauce de integración laboral. REVESCO. Revista de Estudios Cooperativos, $\mathrm{N}^{\mathrm{o}} 73$, pp. 149-185.

Rodríguez, A. (2015) Algunas consideraciones sobre el ánimo de lucro en las cooperativas de iniciativa social. Análisis de su relación con los principios cooperativos. CIRIEC-España, Revista Jurídica de Economía Social y Cooperativa, $\mathrm{N}^{\mathrm{o}} 26$, pp. 1-46.

Rodríguez, A., y Ortega, A. (2008) Algunas consideraciones sobre las cooperativas de iniciativa social en el marco del fomento de empleo y la inserción laboral. CIRIEC-España, Revista Jurídica de Economía Social y Cooperativa, ${ }^{\circ}$ 19 , pp. 55-77.

Salamon, L., y Sokolowski, W. (2016) Beyond Nonprofits: Re-conceptualizing the third sector. Voluntas: International Journal of Voluntary and Nonprofit Organizations, $\mathrm{N}^{\mathrm{o}} 27$, Vol. 4, pp. 1515-45.

Spear, R. (2006) Social entrepreneurship: a different model? International Journal of Social Economics, № 33,399 410.

Spear, R., Cornforth, C., y Aiken, M. (2009) The governance challenges of social enterprises: Evidence from a UK empirical study. Annals of Public and Cooperative Economics, $\mathrm{N}^{\circ}$ 80, Vol. 2, pp. 247-273.

Teasdale, S. (2012) What's in a name? Making sense of social enterprise discourses. Public Policy and Administration, No 27, Vol. 2, pp. 99-119.

Thomas, A. (2004) The Rise of Social Cooperatives in Italy. Voluntas: International Journal of Voluntary and Nonprofit Organizations, № 15, Vol. 3, pp. 243-263.

Wilkinson, C. (2015) A Map of Social Enterprises and Their Ecosystems in Europe. Luxembourg: European Commission. 